\title{
Work in the 21st Century
}

How Do I Log on? 


\section{THE CHANGING CONTEXT OF MANAGING PEOPLE}

Series Editor: Emma Parry 


\section{Work in the 21st Century}

\section{How Do I Log on?}

By

Peter K. Ross

Griffith University, Queensland, Australia

Susan Ressia

Griffith University, Queensland, Australia

Elizabeth J. Sander

Bond Business School, Queensland, Australia

\section{emerald PUBLISHING}

United Kingdom - North America - Japan - India - Malaysia - China 
Emerald Publishing Limited

Howard House, Wagon Lane, Bingley BD16 1WA, UK

First edition 2017

Copyright (C) 2017 Emerald Publishing Limited

Reprints and permissions service

Contact: permissions@emeraldinsight.com

No part of this book may be reproduced, stored in a retrieval system, transmitted in any form or by any means electronic, mechanical, photocopying, recording, or otherwise without either the prior written permission of the publisher or a licence permitting restricted copying issued in the United Kingdom by The Copyright Licensing Agency and in the United States of America by The Copyright Clearance Center. Any opinions expressed in the chapters are those of the authors. Whilst Emerald makes every effort to ensure the quality and accuracy of its content, Emerald makes no representation implied or otherwise, as to the chapters' suitability and application and disclaims any warranties, express or implied, to their use.

\section{British Library Cataloguing in Publication Data}

A catalogue record for this book is available from the British Library

ISBN: 978-1-78714-578-8 (Print)

ISBN: 978-1-78714-577-1 (Online)

ISBN: 978-1-78714-982-3 (Epub)

ISOQAR certified Management System, awarded to Emerald for adherence to Environmental standard 


\section{List of Tables}

Chapter 2

Table 2.1 Employee and Employer Benefits of

Teleworking Practices. . . . . . . . . . 23

Chapter 3

Table 3.1 Differing Coworking Center Characteristics.. . 39

Table 3.2 Coworking Stakeholders. . . . . . . . . . 43

Chapter 5

Table 5.1 Environmental and Institutional Constraints. . 76

Table 5.2 Three Levels of the Digital Divide. . . . . . . 81

Table 5.3 ICT Access - Considerations for Women Entrepreneurs. ........... 82

Chapter 6

Table 6.1 Outsourcing and Offshoring Models and Governance Modes. . . . . . . . . . . 90

Table 6.2 OEL Job Classifications being Outsourced to the Philippines by Australian Firms. . . . . . . 104

Table 6.3 Top Five Countries for Online Workers (2013). 108 


\section{List of Figures}

Chapter 2

Figure 2.1 Four Pillars of NWW. . . . . . . . . . . . 25

Figure 2.2 ICT Adoption - Psychological Ownership

Factors. . . . . . . . . . . 28

Chapter 3

Figure 3.1 Coworking: Between Home and Office. . . . 35

Figure 3.2 Good Neighbors versus Good Partners. . . . 40

Chapter 4

Figure 4.1 Cloud Computing and Entrepreneurship. . . 51

Chapter 7

Figure 7.1 Big Data Precursors. . . . . . . . . . . 116

Figure 7.2 Data, Information Flows, and Evidence-Based

Decision-Making. . . . . . . . . . 120

Conclusion

Figure C.1 Cloud Technologies as Enablers and

Facilitators of New Workplace Institutions

and Frameworks. . . . . . . . . . . 140

Figure C.2 Workplace and Labor Market Themes. . . . 141 


\section{Abbreviations}

AI

artificial intelligence

BAG

born again global (firm)

$\mathrm{BPO}$

business process outsourcing

$\mathrm{CIO}$

Chief Information Officer

CPU

central processing unit

DDM

data driven management

DraaS

Disaster recovery as a service

EPIC

Entrepreneurship Program for Innovation in the Caribbean

FDI foreign direct investment

GEM Global Entrepreneurship Monitor

GFC global financial crisis

GVLMs global virtual labor markets

HBB home-based business

HIT human intelligence task

HR human resource

HRM human resource management

ICT information and communication technology

IaaS Infrastructure as a service (IaaS)

KPO knowledge process outsourcing

KPIs key performance indicators

IP internet protocol

IP rights intellectual property rights

IR industrial relations

LAPD Los Angeles Police Department

LPT Labor process theory

M\&A merger and acquisition

MNE multinational enterprise 
NEIS New Enterprise Incentive Scheme

NGS next generation sequencing

NSA National Security Agency

NWW new ways of working

OECD Organisation for Economic Cooperation and Development

OEL offshore employee leasing

OH\&S occupational health and safety

PaaS Platform as a service

PAPT Patient Admission Prediction Tool

PEO Professional Employer Organisation

R\&D research and development

SITIA Queensland Government Department of Science, Information Technology, Innovation and the Arts (SITIA)

SLA service level agreement

SME small- and medium-sized enterprise

SaaS Software as a service (SaaS)

UBI universal basic income

WEF World Economic Forum

WINC Women Innovators Network in the Caribbean

WFC work/family conflict 


\section{Acknowledgments}

Chapter 3 is derived in part from the following article:

Ross, P.K., \& Ressia, S. (2015). Neither office nor home: Coworking as an emerging workplace choice. The Employment Relations Record, 14(1), 42-57.

Chapter 4 is derived in part from the following article:

Ross, P.K., \& Blumenstein, M. (2015). Cloud computing as a facilitator of SME entrepreneurship. Technology Analysis and Strategic Management, 27(1), 87-101. Retrieved from http:// wwww.tandfonline.com/ http://dx.doi.org/10.1080/09537325. 2014.951621. 


\section{Foreword}

T $\mathrm{t}$ is with great pleasure that I introduce to you the second book in our series on The Changing Context of Managing 1 People. In this text, Ross, Ressia, and Sander provide us with a fascinating analysis of how the changing context, primarily the technological context, both drives and facilitates changes in the way that we work. This notion of an interplay between technological change and the nature of work is central to the purpose of this book series - to examine the implications of the changing external context on the way that we work, and thus the implications for how we manage work and the people who undertake it.

Few would argue with the fact that technological advancements, such as those discussed in this book, have revolutionized the way that we work. As the authors of this text state "the world of work is not going to be disrupted, it is disrupted, with more disturbance to come." Changes such as the increased capacity for the storage and production of data, and the ability to connect to others regardless of time and place has certainly had wide reaching effects on both individuals and workplaces. We see both positive effects - increased communication and collaboration, breaking down of global borders, and flexibility in relation to time and place of work - and negative effects such as an overload of information and the blurring of boundaries between work and non-work life.

This book discusses both the positive and negative implications of technological change. More importantly though perhaps, it also starts to paint the complex picture of how technological changes are intertwined with other changes in the workplace such as the increased emphasis on entrepreneurship and changes to workplace structures. As such, it makes an interesting contribution to both this series and to the conversation about the future of work more broadly, and helps us to forward the mission of this series to help those of us who undertake research, 
xviii FOREWORD

teach, or work in human resource management keep up with the changing world of work and its impact on people management. I am therefore delighted to have been able to include it and to introduce it to you here.

Emma Parry

Series Editor 


\section{Introduction: Work in the 21st Century: How do I Log on?}

$\Psi$ ow do we $\log$ on to work in the 21st century? This question underpins the dilemma faced by governments, organisations, and individuals as they struggle to adapt to the profound changes occurring to workplaces in an era of technologically advanced globally competitive labor markets. This includes shifts towards intermittent precarious type work and self-employment (Standing, 2011), rapid increases in the scope and breadth of information and communication technology (ICT)-supported work activities, the rise of the "gig" economy and the emergence of disruptive technologies that are redefining the relationship between workers and machines. Skilled migration programs add a further dimension to the global labor market mix.

Given that work is a ubiquitous part of human life, with most of us spending a considerable part of our life either at work and/or engaged in work-related activities (Svendsen, 2016), better understanding these emerging labor market changes and work practices could be considered an almost universal need. The blurring of work and private life, brought about in part by the rapid adoption of smart phones and tablets, also means that workrelated activates are increasingly occurring outside of traditional workplaces and/or office hours.

Further, while the nature of work has always been subject to change, the concomitant impacts of globalization, financial, and labor market deregulation and rapid technological advances have rapidly accelerated the pace of such change (Duncan et al., 2016; WEF, 2016). Organizations typically use such advances to reduce labor costs and improve process efficiencies. These strategies may then significantly impact on labor markets and, perhaps more importantly, upon the employees who may become the casualties of workplace changes. Workers then need to consider strategies that will better support their employability and incomes within 
changing labor market contexts. This may require a greater emphasis on self-employment and entrepreneurial opportunities, as alternatives to traditional employer/employee relationships.

The need for increased public discussion on these issues was reinforced by the findings of a World Economic Forum survey of Chief Human Resource Officers (CHROs) across almost 400 multinational enterprises (MNEs), which found the main perceived economic and technical drivers of workplace and labor market transformations to be changing work environments, flexible working arrangements, telework, Cloud technologies, advances in computing power and big data (WEF, 2016, pp. 6-7); all topics examined by this book (see also Ross \& Blumenstein, 2013, 2015; Ross \& Ressia, 2015; Sander et al., 2014).

Changing workplace layouts, telework practices, and the rise of coworking centers, for example, reflect changes that are occurring to the physical work environment and its location. The adage, "work is a thing you do, not a place you go" is further evidenced by the emergence of the "the human Cloud," which links firms to workers across the globe, allowing even relatively small firms to engage in offshored outsourcing strategies. Relatively cheap access to Cloud-based scalable services are concurrently fostering nimble entrepreneurship and global start-up cultures, while data analytics, artificial intelligence (AI), and automation question the very nature of work itself.

Governments, practitioners, workers, and academics then need to better understand how to harness the benefits and meet the challenges of these changing workplace contexts, as the world enters what has been termed the "fourth industrial revolution" (WEF, 2016). Governments, in this regard, must design effective policies and legislative frameworks to deal with rapid technological change and associated organizational strategies and work practices. They further need to consider the impacts of these changes across the wider population. Different worker cohorts, for example, may be positively or negatively affected by these changes depending on education and skills levels, socio-economic backgrounds, regional or country location, and gender.

Governments then need to develop policies that better support worker cohorts that are likely to be negatively affected by impending changes to labor markets and working conditions. Traditional legal distinctions between employed and selfemployed workers, for example, may no longer provide sufficient protections for people working in the emerging "gig economy," 
with questions being raised about the longer-term impacts of algorithmic management systems, such as the Uber ride sharing App, on employment conditions for so-called "self-employed" workers (Duncan et al., 2016, p. 1; Davidov, in press). Predictions of large-scale technological unemployment resulting from the rise of $\mathrm{AI}$ and automation raise further questions about the ability of governments to meet these forecast challenges.

Firms similarly need to ensure that their strategies align with changing work practices and frameworks. Failure to do so potentially puts them at a disadvantage vis-a-vis their competitors (or in the case of governments, with competitor nations), including their ability to attract and retain talent. In contrast, a greater understanding of these issues allows organizations to better grasp the opportunities and overcome the challenges that these changes present.

Further, while technical efficiency remains important, new technologies merely provide the underlying infrastructure that may facilitate new strategies and practices (Ross, 2015). Simply going out and buying the latest overhyped technology may therefore do little for an organization (or may in fact have negative consequences). Rather, managers need to understand both the potential benefits and limitations of new technologies and how they may better support overall organizational objectives (Kodama, 2012; Ross \& Blumenstein, 2013).

Academics also need to keep their research relevant if they are to continue to provide valued input into government and industry policy making processes, as the traditional industrial relations (IR) rhetoric that continues to haunt much of the employment relations literature becomes increasingly less applicable to larger sections of the workforce. The authors acknowledge that some IR researchers may be disappointed that the book does not contain a chapter on the role of trade unions in the changing world of work. This is not to undervalue the role of unions. Far from it, the authors fully understand and respect their role in labor markets. Rather, the book purposely set out to examine these issues outside of traditional management/union IR contexts, which are often steeped in 20th century frameworks that may not be well-suited to examining these emerging issues. Paradoxically, we are entering an era where research into employment relations and the changing world of work is more important than it has ever been. This book therefore seeks to broaden academic debate and further consider how existing tools and knowledge can be further developed to better analyze the 
underlying institutions and frameworks that are facilitating profound changes in the way in which people and organizations work.

What then do 21st century workplaces look like and what factors support these workplace changes? In examining these issues this book does not aim to be simply another speculative "future of work" book per se. Rather, it seeks to identify and examine institutions, frameworks, and technologies that are emerging to support new work practices, an area that has been underexamined to date (Ross \& Blumenstein, 2013). Much of the book therefore examines workplace and labor market changes that have already begun. Throughout the text, the authors analyze issues and develop frameworks that are underpinned by empirical evidence. This then provides a basis upon which to consider the future potential implications of these changes.

This approach aims to provide practical information and knowledge for policy makers, managers, and workers trying to better understand the processes underpinning changing work environments, while further developing academic perspectives and theoretical debate on the institutions and technologies supporting the changing nature of work and workplaces in the 21 st century. The book further aims to provide a reference for students and the broader public who are looking to better understand the changing nature of the world of work.

\section{Coverage and Structure of the Book}

The book is divided into the following three sections that aim to identify, examine, and better coordinate emerging workplace and labor market issues into a cohesive interlinked text.

\section{SECTION 1: THE CHANGING WORK ENVIRONMENT}

Section 1 examines the impact of changing physical work environments on work practices. Chapter 1 begins the section by examining how the spacial design of physical workplaces may impact on worker productivity and well-being. It further shows that despite increasing shifts towards telework and mobile workforces (as outlined in Chapters 2 and 3), organizations are still investing significant amounts of time and capital into developing centralized workplaces. Two factors help to explain this changed 
outlook. First, the physical work environment is now linked to organizational performance and innovation (Davis, Leach, \& Clegg, 2011). Second, the tangible workspace remains the second largest organizational overhead after payroll (McCoy, 2005), which has led to workplace strategies that aim to reduce these costs. These key factors have underpinned the significant changes that have occurred to physical work environments over the past 10 years (Davis et al., 2011; Elsbach \& Pratt, 2007). They have further led to a plethora of consultants now operating in this space (no pun intended!). The chapter draws together emerging theories in these areas and analyzes how different workplace layouts and designs may influence employee productivity, job satisfaction, and well-being.

Chapter 2 further discusses changes to the work environment through an examination of potential benefits, opportunities, and challenges related to the adoption and greater use of ICTsupported workplace collaborative technologies across organizations and associated shifts towards mobile and teleworking practices. The chapter outlines how these changes require managers and workers to develop the skills and mind-set required to effectively operate in virtual environments, as technological proximity increasingly supersedes geographical proximity across organisations and workplaces (Melissaratos \& Slabbert, 2010, pp. 204-217; West, 2016; Wrike, 2012). Work then increasingly becomes "a thing you do, rather than a specific location that you go to" (Melissaratos \& Slabbert, 2010, pp. 204-217; West, 2016; Wrike, 2012).

The chapter outlines how trust may be a major barrier to the effective implementation of mobile and teleworking arrangements. The technologies being introduced also tend to heighten managements' ability to track and monitor their employees' activities, which in turn raises ethical and legal issues in relation to their introduction and use. The potential benefits of telework in terms of improved work/life balance and flexible work practices also need to be balanced against possible work intensification and employee burnout brought about by employees potentially being online 24/7.

Chapter 3 then discusses changes to the work environment in relation to a range of new and related work practices that have been dubbed "coworking." Characterized by open-space work environments, coworking centers lie between working from home and working in traditional office environments. They provide excellent examples of how new workplace spatial designs 
allied to ICT-supported workplace collaborative technologies (as outlined and discussed in Chapters 1 and 2), are supporting new work practices (Andrade, Ares, Suarez, \& Giret, 2013; Ross \& Blumenstein, 2013, 2015).

The chapter considers the drivers behind the rapid increase in the use of coworking spaces and attempts to better categorize the eclectic organizations that presently operate under this moniker, ranging from coffee shops and community spaces to professionally run coworking spaces and start-up incubators (the latter are linked to entrepreneurial behavior as discussed in Section 2). The chapter further contrasts and compares collaborative "coworking communities" with more individually oriented noncollaborative alternative office spaces.

\section{SECTION 2: ENTREPRENEURSHIP: SELF-EMPLOYMENT IN GLOBALLY COMPETITIVE PRODUCT AND LABOR MARKETS}

Section 2 of the book focuses on entrepreneurship and selfemployment. As outlined in further detail in Section 3 below, researchers suggest that workers may be increasingly required to create their own businesses to counter the potential loss of traditional paid jobs due to increasingly competitive global labor markets and the rapid development and deployment of AI and automation (Hamilton, 2016, pp. 95-96; Koebler, 2014). Entrepreneurship has therefore been promoted as a vehicle to support continued economic development, rising living standards, and job creation in in an era of increasingly competitive global product and labor markets (Audretsch, Keilbach, \& Lehmann, 2006; Hussain, Sultan, \& Ilyas, 2011; Parker, 2009; van Praag \& Versloot, 2008).

Chapter 4 begins the section by examining how Cloud technologies facilitate the development of internationally orientated (born global) small- and medium-sized enterprise (SME) entrepreneurship. Three broad questions guide this discussion. First, how do Cloud technologies support and bolster entrepreneurship and innovation? Second, to what extent do Cloud technologies foster an international entrepreneurial orientation? Third, what is the capacity of Cloud technologies to "level the playing field" between SMEs and larger firms, including multinational enterprises (MNEs)?

In this regard, the rapid adoption of Cloud-based ICT services reflects a Schumpeterian creative destruction scenario that provide SMEs and start-up firms with greater access to global 
markets and lowered opportunity costs. They further support collaboration and innovation in an increasingly interconnected world.

Chapter 5 then examines whether self-employment and entrepreneurial activities may be a vehicle to address labor market discrimination challenges that are often faced by women and migrant workers, which makes it more difficult for these groups to access employment opportunities in traditional labor markets. From a gendered perspective, female migrant workers may experience the double burden of being both migrant and female in the labor market, which has been described as the "double disadvantage" (Alcorso \& Ho, 2006; Azmat, 2014; Boucher, 2006; Collins \& Low, 2010; Kofman \& Raghuram, 2006a; Meares, 2010; Pereira, 2012; Ressia, 2010). The chapter therefore examines the developing literature around the entrepreneurship of women and migrant groups, and how new technologies and government policy may support such activities (Collins \& Low, 2010; de Vries, 2014), which in turn may benefit the wider community.

\section{SECTION 3: GLOBAL VIRTUAL LABOR MARKETS AND THE RISE OF THE MACHINES}

Section 3 examines the impact of emerging "disruptive" technologies on organizational strategies, work practices, and labor markets. These technologies include Cloud-based platforms, Big Data Analytics, AI, and Automation.

Chapter 6 builds on the Cloud computing concepts examined in Chapter 4, by examining how the human Cloud and offshore employee leasing (OEL) labor market models are changing the way that firms engage and manage workers, as firms increasingly leverage the skills on offer in global virtual labor markets (GVLMs). Human Cloud and OEL approaches further add an international dimension to the virtual teleworker models outlined in Chapter 2.

The chapter examines differing human-Cloud platform governance structures and employment relationships, along with the eclectic range of virtual labor market skills on offer. The chapter further examines the concurrent growth of Cloud-supported OEL models, such as "staff leasing" arrangements that allow firms to "co-manage" overseas-based workers in partnership with BPO firms (Ross, 2016). It also considers the social impacts of these changes, including shifts towards more precarious 
employment and competition between workers in industrialized and developing countries.

Chapter 7 then examines the potentially far reaching impacts of data driven management (DDM), AI, and automation on organizational and workplace practices. These emerging disruptive technologies herald profound changes in how organizations organize, manage, and perform work, as they seek to reduce costs, improve their competitiveness, and develop new markets (OECD, 2015 , p. 17). This includes the fusing of human and machine roles as the era of widespread and pervasive AI-supported automation begins.

The chapter examines how these technologies are being used to support new and changing work practices. This includes an examination of the role of data analytics in organizational decision making, including issues related to machine driven data management bureaucracy and control (Pedersen \& Aagaard, 2015). The chapter further considers how machines and automation are impacting on workplaces and labor markets, as the boost in industrial productivity and output that is feeding the "rise of the machines" reduces the number of people needed to produce that output (Gillies 2015, p. 117). The nature of these rapidly changing technologies requires this chapter to postulate on future potential workplace and labor market changes to a greater extent than other chapters of the book.

\section{CONCLUSIONS: EMERGING CHANGES AND FUTURE DIRECTIONS?}

The conclusion contrasts, compares, and elicits common themes amongst the above chapters in relation to emerging institutions and frameworks. It considers the implications of this research and provides discussion in relation to the opposing questions, "What can technology do for you?," versus "What can technology do to you?" (Gutek, 1983, in Korac-Kakabadse et al., 2001, p. 90). These questions in turn support interesting grounds for conjecture in relation to current and likely future work practices. The conclusion further provides recommendations for policy makers, practitioners, and workers in relation to better addressing the challenges of the 21 st century workplace.

The authors therefore hope that you enjoy our journey into the changing world of work, which begins with an examination of the changing work environment in Section 1. 